\title{
Including the Oxidation State of Iron to Improve Matrix Corrections in EPMA Analyses
}

Emma Bullock ${ }^{1}$, Andrew Locock ${ }^{2}$, Anette von der Handt ${ }^{3}$, John Fournelle ${ }^{4}$, Michael Dungan ${ }^{5}$ and John Donovan $^{5}$

${ }^{1}$ Carnegie Institution for Science, Washington, District of Columbia, United States, ${ }^{2}$ University of Alberta, Edmonton, Alberta, Canada, ${ }^{3}$ University of Minnesota, Minneapolis, Minnesota, United States, ${ }^{4}$ University of Wisconsin, Madison, Madison, Wisconsin, United States, ${ }^{5}$ University of Oregon, Eugene, Oregon, United States

Iron is the fourth most abundant element found in the Earth's crust, making it an important component of many minerals [e.g. 1, 2]. Iron found in rocks at the Earth's surface predominantly exists in one of two valence states: $\mathrm{Fe}^{2+}$ (ferrous iron) and $\mathrm{Fe}^{3+}$ (ferric iron). The ratio of ferrous to ferric iron in a mineral can provide information on the conditions under which iron-bearing minerals formed, allowing us to infer conditions such as temperature and oxygen fugacity in regions of the Earth that we might not be able to directly sample, such as the Earth's mantle [e.g. 2, 3].

The electron microprobe (EPMA) is a commonly-used analytical tool used to determine major, minor and trace element abundances in geological materials. Traditionally, analysis of iron in rocks assumes that all iron present has a common valence state, often $\mathrm{Fe}^{2+}$, and thus oxygen is calculated to be associated with the iron in a 1:1 ratio, as FeO. This assumption works well for many minerals, such as fayalite $(\mathrm{Fe}, \mathrm{Mg})_{2} \mathrm{SiO}_{4}$, and ferrosilite $(\mathrm{Fe}, \mathrm{Mg})_{2} \mathrm{Si}_{2} \mathrm{O}_{6}$, in which iron typically only has one valence state (ferrous iron). However, some geologically important minerals, such as amphibole and garnet, contain iron in both ferrous and ferric states. This issue is generally even more important for analyses of cubic and rhombohedral Fe-Ti oxides. The assumption that total iron is entirely $\mathrm{Fe}^{2+}$ for minerals that contain both ferric and ferrous iron leads to erroneous results for a number of reasons. This simplistic approach violates charge-balance and leads to an incorrect calculation of $\mathrm{O}$, which in turn perturbs matrix corrections because oxygen absorbs Fe X-rays. Where insufficient oxygen is used in the course of matrix corrections, the reported total iron will be lower than the correct value.

We have implemented a new routine that determines iteratively the ratio of ferric to ferrous iron from an electron probe analysis using the Probe for EPMA software, so that the appropriate amount of oxygen can be assigned, the appropriate matrix correction for the analysis can be performed, and a more accurate report of the elements present produced. The calculations for determining the amounts of ferrous versus ferric iron are based on the method of [4], using stoichiometric criteria. Electron microprobe analyses are collected as per usual, but there is now an option to calculate excess oxygen from ferric/ferrous ratios in the Analyze window of Probe for EPMA.

To demonstrate the importance of including such a routine as part of the matrix correction iterative loop instead of during post-processing, we can take the case of a simple iron oxide, such as magnetite $\left(\mathrm{Fe}_{3} \mathrm{O}_{4}\right)$, which contains both $\mathrm{Fe}^{2+}$ and $\mathrm{Fe}^{3+}$. If we analyze this magnetite with all Fe calculated as $\mathrm{FeO}$, we get low totals of $92.65 \mathrm{wt} \%$ (Table 1). Including the calculation for excess $\mathrm{O}$ in an Excel spreadsheet based on the method of [4], we can see that $33.3 \%$ is present as $\mathrm{Fe}^{2+}$, while $66.6 \%$ is present as $\mathrm{Fe}^{3+}$, giving us 30.99 
wt $\% \mathrm{FeO}$, and $68.53 \mathrm{wt} \% \mathrm{Fe}_{2} \mathrm{O}_{3}$. However, the excess oxygen is not taken into account during the matrix corrections. If we perform the same task using Probe for EPMA, we can see that the excess $\mathrm{O}$ present has an effect on the amount of iron detected in the analysis (Table 1); 31.28\% FeO, and 69.17 wt $\% \mathrm{Fe}_{2} \mathrm{O}_{3}$. This corresponds to a change in the total iron content (as FeO) measured in the magnetite of $0.87 \mathrm{wt} \%$ (Table 2).

We can do the same for ilmenite (ideally $\mathrm{FeTiO}_{3}$ ). In our ilmenite samples, between $4 \%$ and $20 \% \mathrm{Fe}$ is present as $\mathrm{Fe}^{3+}$ (Table 1). This still has an effect on the matrix correction, although the results are less dramatic; Zagi Mountain contains $0.01 \mathrm{wt} \%$ more iron (as $\mathrm{FeO}$ ) when matrix effects are taken into account, versus $0.05 \mathrm{wt} \%$ in the NMNH sample (Table 2; Figure 1).

These data illustrate the importance of including excess oxygen in the matrix correction calculations in order to accurately determine accurate element concentrations. Future work will expand the suite of minerals analyzed to include more complex samples such as garnet and amphibole.

\begin{tabular}{|c|c|c|c|c|c|c|c|c|c|c|c|c|c|c|c|}
\hline Sample & ID & $\mathrm{MgO}$ & $\mathrm{SiO}_{2}$ & $\mathrm{TiO}_{2}$ & $\mathrm{~V}_{2} \mathrm{O}_{3}$ & $\mathrm{MnO}$ & FeO total & $\mathrm{ZnO}$ & $\mathrm{Nb}_{2} \mathrm{O}_{5}$ & initial sum & $\mathrm{FeO}$ & $\mathrm{Fe}_{2} \mathrm{O}_{3}$ & $\mathrm{Fe}^{3+} / \Sigma \mathrm{Fe}$ & Total & Excess 0 \\
\hline Zagi Mtn & no ferric calc & & & 51.23 & & 18.54 & 28.55 & 0.38 & 0.38 & 99.08 & 27.39 & 1.30 & $4.1 \%$ & 99.21 & 0.13 \\
\hline$n=40$ & std dev & & & 0.12 & & 0.05 & 0.05 & 0.01 & 0.02 & & & & & & \\
\hline Zagi Mtn & PFE ferric calc & & & 51.23 & & 18.54 & 28.56 & 0.38 & 0.38 & 99.09 & 27.39 & 1.31 & $4.1 \%$ & 99.22 & 0.13 \\
\hline$n=40$ & std dev & & & 0.12 & & 0.05 & 0.05 & 0.01 & 0.02 & & & & & & 0.01 \\
\hline NMNH 96189 & no ferric calc & 0.32 & & 46.17 & & 4.62 & 46.54 & 0.06 & 0.7 & 98.41 & 36.99 & 10.62 & $20.5 \%$ & 99.47 & 1.06 \\
\hline$n=58$ & std dev & 0.01 & & 0.22 & & 0.05 & 0.19 & 0.01 & 0.04 & & & & & & \\
\hline NMNH 96189 & PFE ferric calc & 0.32 & & 46.23 & & 4.62 & 46.59 & 0.06 & 0.7 & 98.52 & 37.04 & 10.61 & $20.5 \%$ & 99.58 & 1.06 \\
\hline$n=58$ & std dev & 0.01 & & 0.22 & & 0.05 & 0.19 & 0.01 & 0.04 & & & & & & 0.03 \\
\hline Kiruna & no ferric calc & & 0.04 & & 0.22 & 0.04 & 92.65 & & & 92.95 & 30.99 & 68.53 & $66.6 \%$ & 99.82 & 6.87 \\
\hline$n=30$ & std dev & & 0.02 & & 0.01 & 0.01 & 0.15 & & & & & & & & \\
\hline Kiruna & PFE ferric calc & & 0.04 & & 0.22 & 0.04 & 93.52 & & & 93.82 & 31.28 & 69.17 & $66.6 \%$ & 100.75 & 6.93 \\
\hline$n=30$ & std dev & & 0.02 & & 0.01 & 0.01 & 0.16 & & & & & & & & 0.01 \\
\hline
\end{tabular}

Figure 1. Table 1. Table showing the results of calculating the amount of $\mathrm{FeO}$ versus $\mathrm{Fe} 2 \mathrm{O} 3$ in ilmenite (samples Zagi Mountain and NMNH 96189) and magnetite (Kiruna K-10-02). The results labeled "no ferric calc" were calculated following the method of Droop (1987). The results labeled "PFE ferric calc" were processed using the Droop calculation in Probe for EPMA, then input into the matrix calculations, so that the matrix correction incorporates the excess oxygen.

\begin{tabular}{|cccc|}
\hline & Excess $\mathrm{O}$ & $\Delta \mathrm{FeO}_{\text {tot }}$ & std dev Excess O \\
\hline Zagi Mtn & 0.13 & 0.01 & 0.01 \\
NMNH 96189 & 1.06 & 0.05 & 0.03 \\
Kiruna & 6.93 & 0.87 & 0.01 \\
\hline
\end{tabular}

Figure 2. Table 2. Table showing excess oxygen, and the effect that including the extra oxygen had on the matrix calculation, and thus the determination of total iron.

\section{References}

[1] Taylor, SR (1964) Geochimica et Cosmochimica Acta, pp1273-1285.

[2] McCammon, CA et al (2004) Phys. of Earth and Planetary Interiors, pp157-169.

[3] Cottrell, E \& Kelley, KA (2011) Earth and Planetary Science Letters, pp270-282.

[4] Droop, GTR (1987) Mineralogical Magazine pp431-435. 